\title{
El Grupo de Estudios del exilio literario : Crónica del Congreso "El
} exilio literario español del 1939"

Manuel Aznar soler

\section{Citer ce document / Cite this document :}

Aznar soler Manuel. El Grupo de Estudios del exilio literario : Crónica del Congreso "El exilio literario español del 1939". In: Exils et migrations ibériques au XXe siècle, n³-4, 1997. pp. 191-194;

doi : https://doi.org/10.3406/emixx.1997.1105

https://www.persee.fr/doc/emixx_1245-2300_1997_num_2_3_1105

Fichier pdf généré le 28/08/2018 


\section{El Grupo de Estudios del exilio literario : Cronica del Congreso "El exilio literario español de 1939"}

Manuel Aznar Soler

Director del GEXEL

Entre el 27 de noviembre y el 1 de diciembre del pasado año de 1995 se celebró en el Auditorio de la Facultad de Letras de la Universitat Autònoma de Barcelona (UAB) el Primer Congreso Internacional sobre El exilio literario español de 1939, organizado por el Grupo de Estudios del Exilio Literario (GEXEL) y en el que intervinieron más de un centenar de escritores e investigadores sobre el tema.

EL GEXEL es un grupo de investigación adscrito al Departamento de Filología Española de la UAB, que se constituyó formalmente el 30 de enero de 1993 con la aprobación por parte de sus miembros fundadores de un Manifiesto que constituye su acta de nacimiento y su declaración de objetivos. Conviene transcribir fragmentariamente alguno de sus párrafos iniciales:

EL GEXEL (...) se plantea como tarea prioritaria y urgente -una tarea de evidentes implicaciones éticas y políticas- la reconstrucción de la memoria histórica, cultural y literaria del exilio español de 1939. Cuando la guerra civil ya no es para la mayoría de la sociedad sino un capítulo más en la historia del siglo $\mathrm{XX}$, constatamos que en nuestra literatura parece no haber terminado.

El mejor homenaje a un escritor, vivo o muerto, consiste en leerlo, tarea particularmente dificil en el caso del exilio. Al margen de aquellos autores cuya obra ha sido total o parcialmente recuperada, una gran parte de nuestros escritores exiliados nos son aún hoy inaccesibles, ya que muchos de sus libros no figuran en bibliotecas públicas, catálogos editoriales 0 librerías. En suma, que la mayoría de nuestros escritores exiliados, a quienes la política del franquismo condenó al silencio y al olvido, siguen siendo escritores ignorados. 
Apelamos a la conciencia y a la sensibilidad de la sociedad española para que repare esta injusticia y salde, de una vez por todas y con la debida dignidad, esa deuda moral contraída con aquellos españoles que pagaron con el destierro forzoso su fidelidad a la legalidad democrática republicana y su defensa de la libertad de nuestra cultura. Apelamos a la necesidad y urgencia de recuperar este patrimonio cultural y literario. Olvidarse del exilio, ahora que aún puede reconstruirse buena parte de su historia documental y literaria, sería su segunda muerte, acaso ya definitiva.

Estamos firmemente convencidos de que la recuperación de nuestro exilio debería haber sido una cuestión de política de Estado y de que, salvo iniciativas puntuales cuyo mérito sería injusto no reconocer, el exilio constituye una asignatura pendiente de la política cultural de la España democrática $\mathrm{y}$, especialmente, de un gobierno cuyo partido luchó en defensa de aquellos mismos valores. Estamos firmemente convencidos de que la recuperación del exilio no puede quedar abandonada únicamente a la iniciativa privada, por bienintencionada que ésta sea, y por ello recabamos la ayuda para nuestro proyecto de las instituciones del Estado: Gobierno Central, Gobiernos Autonómicos, Diputaciones Provinciales y Ayuntamientos.

Nos gustaría que el pueblo español pudiese leer lo antes posible a los escritores del exilio cuyas obras aún no han sido reeditadas y que esta literatura desterrada regresara a su tierra y a su público, es decir, estuviera a su alcance en las librerías o bibliotecas sin otro criterio que el de su calidad.

Durante el año 1993 y con la ayuda del Ministerio de Cultura, el GEXEL organizó un ciclo de Presencias literarias en la Universidad, con la participación, entre otros, de escritores exiliados como Virgilio Botella Pastor, Eugenio F. Granell y Rosa Chacel, fallecida en Madrid el 27 de julio de 1994. Como clausura del ciclo se celebró los días 9 y 10 de diciembre el I Simposio sobre El exilio literario español de 1939. Homenaje a Max Aub, que sirvió como presentación pública de los investigadores del GEXEL.

En octubre de 1994 la Dirección General de Investigación Científica y Técnica (DGICYT) del Ministerio de Educación y Ciencia nos aprobó la financiación de un proyecto de Investigación (PB93-0835) cuyo objetivo final consiste en la publicación de un Diccionario bio-bibliográfico de los escritores del exilio español de 1939, trabajo que hemos iniciado por Argentina y México y que actualmente constituye nuestra prioridad máxima.

La organización del Congreso ha supuesto el cumplimiento por parte del GEXEL de uno de los objetivos expuestos en su manifiesto fundacional. Porque, sin triunfalismos de ninguna clase y antes un numeroso público compuesto mayoritariamente por jóvenes estudiantes que siguieron con vivo interés sus maratonianas sesiones y que, tan espontánea como emotivamente, quisieron homenajear en la clausura a los escritores exiliados 
con un ramo de catorce rosas abrileñas-, Bellaterra vino a convertirse durante aquella semana en un espacio de encuentro cálido y fecundo, tanto intelectual como humanamente, entre los escritores y los investigadores del exilio literario español de 1939. Así, gracias al esfuerzo colectivo del Comité de Organización y del Equipo de Colaboradores, aquel sueño de 1993 se convirtió esa última semana de noviembre de 1995 en realidad, en una hermosa realidad tricolor como la bandera que presidió sus sesiones, la bandera por la que muchos españoles, leales a la legalidad democrática republicana, lucharon y murieron durante la guerra civil y el exilio en defensa de la cultura, la dignidad y la libertad.

Porque el GEXEL no puede ni quiere silenciar que este Primer Congreso Internacional constituyó también un Homenaje a nuestro exilio republicano de 1939, a la calidad humana y dignidad política de todos nuestros exiliados sin exclusiones: desde el obrero al intelectual o desde el campesino al escritor, hablaran en cualquiera de las cuatro lenguas de la República. Lejos de cualquier clase de sectarismo, la prestigiosa nómina del Comité de Honor -por orden alfabético, de Rafael Alberti a Ramón Xirau- venía a expresar la pluralidad política y lingüística de nuestro exilio literario.

$Y$ como la calidad de un grupo de investigación se define por la calidad de sus publicaciones, con motivo del Congreso han aparecido las cuatro primeras publicaciones del GEXEL, uno de cuyos objetivos fundamentales consiste, claro está, en embarcar libros. Pues bien, los cuatro primeros (Sinaia-1, Ipanema-1, Winnipeg-1 y Winnipeg-2), que zarparon en el verano de 1995 de puertos europeos y americanos cargados de memoria literaria para atravesar el océano del olvido, llegaron al puerto de Bellaterra el pasado noviembre y son éstos : Las literaturas exiliadas de 1939, edición de M. Aznar Soler, número 1 de la colección Sinaia, una publicación colectiva en donde avanzamos el primer borrador de La Biblioteca del Exilio Literario que nuestro GEXEL pretende reconstruir y que incluye también un breve informe sobre la literatura en lenguas castellana, catalana, gallega y vasca ; En aquella Valencia, una novela inédita de Esteban Salazar Chapela en edición de Francisca Montiel Rayo, número 1 de la colección Ipanema, dedicada a nuestra narrativa exiliada ; Cuatro imposibles, de José Ricardo Morales en edición de Claudia Ortego Sanmartín, número 1 de la colección de teatro, bautizada Winnipeg en homenaje al barco que condujo en 1939 a Chile a un grupo de exiliados republicanos españoles, entre los cuales estaba el entonces joven José Ricardo Morales.

Un libro suyo, que recoge tres obras inéditas (Colón a toda costa o el arte de marear, "desvarío dramático en tres jornadas"; La corrupción al alcance de todos, "farsa en un acto", y El oniroscopio, "Farsa en un acto cívico-militar", constituye el buque-insignia de nuestra flotilla dramática e inaugura las travesías teatrales del GEXEL, al que hay que añadir como número 2 La libertad en el tejado, un "auto" de María Teresa León en edición de M. Aznar Soler. 
Es obvio que un Congreso sobre el exilio literario español de 1939 no podía agotar sus objetivos en un ámbito exclusivamente académico. Por ello, además de las diez sesiones de comunicaciones y ponencias -entre las cuales cabe resaltar las intervenciones de escritores exiliados como Carlos Blanco Aguinaga, José Ricardo morales o Enrique de Rivas- quiero destacar algunas actividades paralelas: por ejemplo, las dos mesas redondas de "Testimonios", con la participación de Avel.lí Artís Gener (Tísner), Alejandro Finisterre, Jacinto Luis Guereña, Rafael Martínez Nadal, Angelina Muñiz-Huberman, Francisca Perujo, Luis Alberto Quesada, Roberto Ruiz y Julio Sanz Sainz; la representación de Las horas contadas, de José Ricardo Morales, seguida de un Recital poético en el que leyeron sus propios versos Blanco Aguinaga, Finisterre, Guereña, Jesús López Pacheco, Muñiz-Huberman, Perujo, Quesada y Enrique de Rivas; la representación de Memoria de la melancolía, recital poético con acompañamiento musical basado en fragmentos del libro de María Teresa León y de una selección de poemas de Rafael Alberti, interpretado por Javier Egea, Susana Oviedo y el quinteto Amati o, ya por último, la proyección del Vídeo Exilios: refugiados españoles en el Mediodía de Francia, presentado por Alicia Alted y Antonio Risco.

Finalmente, en la sesión de clausura se anunció la publicación en las Actas de los materiales seleccionados por el Comité Científico, así como la convocatoria del Segundo congreso internacional para el año 1999, sesenta aniversario del exilio republicano de 1939. 